\title{
Mechanisms and therapeutic potential of interactions between human amyloids and viruses
}

\author{
Emiel Michiels ${ }^{1,2} \cdot$ Frederic Rousseau $^{1,2} \cdot$ Joost Schymkowitz ${ }^{1,2} \mathbb{C}$
}

Received: 31 July 2020 / Revised: 21 October 2020 / Accepted: 11 November 2020 / Published online: 26 November 2020

(C) The Author(s) 2020

\begin{abstract}
The aggregation of specific proteins and their amyloid deposition in affected tissue in disease has been studied for decades assuming a sole pathogenic role of amyloids. It is now clear that amyloids can also encode important cellular functions, one of which involves the interaction potential of amyloids with microbial pathogens, including viruses. Human expressed amyloids have been shown to act both as innate restriction molecules against viruses as well as promoting agents for viral infectivity. The underlying molecular driving forces of such amyloid-virus interactions are not completely understood. Starting from the well-described molecular mechanisms underlying amyloid formation, we here summarize three non-mutually exclusive hypotheses that have been proposed to drive amyloid-virus interactions. Viruses can indirectly drive amyloid depositions by affecting upstream molecular pathways or induce amyloid formation by a direct interaction with the viral surface or specific viral proteins. Finally, we highlight the potential of therapeutic interventions using the sequence specificity of amyloid interactions to drive viral interference.
\end{abstract}

Keywords Protein aggregation $\cdot$ Antiviral $\cdot$ Seeding $\cdot$ Surface-catalyzed nucleation

\section{Introduction}

Ever since the clinical psychiatrist and neuroanatomist Alois Alzheimer reported distinctive plaques and neurofibrillary tangles in the brain of one of his patients in 1906, protein aggregates or amyloids have been widely studied in disease context $[1,2]$. The main reason for this is the deposition of the amyloids in tissues that are affected by the disease. However, these amyloid depositions could still be either a cause or a consequence of the disease [2]. A century has passed and the molecular mechanisms triggering amyloid deposition and their associated toxicity are still not completely understood. However, it is now clear that amyloids per se are not necessarily toxic [3] and studies have shown the existence of functional amyloids that perform important

Frederic Rousseau

Frederic.rousseau@kuleuven.vib.be

$\triangle$ Joost Schymkowitz

Joost.schymkowitz@kuleuven.vib.be

1 VIB Center for Brain and Disease Research, Leuven, Belgium

2 Switch Laboratory, Department of Cellular and Molecular Medicine, KU Leuven, Leuven, Belgium cellular tasks, providing a structural scaffold or aiding in long-term memory consolidation [4]. Recently, it was shown that pathogenic amyloids known for their association with disease might also encode functional roles [5]. The beststudied example of this is the antimicrobial effect of disease-associated amyloids. For example, it was shown that amyloid beta, which plays a central role in Alzheimer's Disease, binds to herpes virion particles and mediates protective antiviral effects [6]. It has even been proposed that the accumulation of amyloid in the brain of Alzheimer patients might be a direct result of this protective effect of amyloid beta against herpesvirus infections [7]. In contrast to the antimicrobial effect of amyloid beta, semen-derived amyloids promote viral infectivity, for example in case of an HIV infection [8]. In summary, many direct and indirect interactions between amyloids and viruses have been described to date. Here, we review these reported interactions between human-expressed amyloidogenic proteins and human-infecting viruses. Moreover, we provide a detailed overview of the potential mechanisms underlying these interactions that have been proposed so far. It has been well established that amyloid formation can initiate spontaneously, via surfacecatalyzed nucleation or by adding preformed aggregates $[9$, 10]. We try to connect these three well-studied molecular 
processes of amyloid initiation to three potential mechanisms of amyloid-virus interactions. Finally, we discuss how amyloid-virus interactions could be exploited for the design of novel antiviral therapeutics.

\section{Amyloids: toxic or functional?}

Protein homeostasis is a central hub in every living cell: the controlled synthesis of a specific amount of protein, the correct folding and localization, and finally the degradation of proteins are essential for cell viability [11-13]. Nevertheless, due to the complexity of protein folding, misfolding and aggregation are inevitable and are inherent to the normal functioning of a cell [14]. Protein aggregation can be the result of one of many factors, including destabilizing mutations, oxidative stress, external stress factors (e.g., heat, chemicals, etc.), or changing metabolic conditions during disease or the aging process $[12,15]$. To cope with the constant pressure of protein misfolding and aggregation, cells have evolved a complex fail-safe network of pathways to ensure proper refolding or degradation of protein aggregates. This network is termed the protein quality control (PQC) system, and includes molecular chaperones, proteasome machinery, and autophagy pathways $[9,16]$. Even though cells can rely on such an extensive PQC system, occasionally, protein aggregation persists and leads to harmful effects. As a result, over 35 proteins or peptides organize into protein aggregates that are associated with human diseases [9].

From the unfolded nascent polypeptide chain exiting the ribosome to the folded native state, a protein molecule can adopt different conformational states and, remarkably, even the native state is often not a highly constrained conformation, but instead resides in a precarious equilibrium [9]. This inherent instability can lead to partial protein unfolding or misfolding. Such misfolded proteins can expose sticky amino acid fragments that are usually buried inside the core of the protein $[17,18]$. As a result, the misfolded proteins tend to co-assemble and form small oligomeric aggregates $[19,20]$. When the aggregation reaction proceeds, oligomers can undergo substantial reorganizations to form compact $\beta$-sheet-containing structures. These preformed aggregate structures can recruit additional monomeric proteins and as such continue the aggregation reaction by self-association. The result of such aggregation reactions is the typical fibrillar architecture observed for amyloids, which are defined as protein aggregates characterized by a cross- $\beta$ core [21]. The sticky amino acid fragments that compose the cross- $\beta$ core of amyloids were named Aggregation-Prone Regions (APRs) and are mostly only 5-15 amino acids in length [17, 22]. It is the self-interaction of these regions that drives the amyloid reaction. Moreover, APRs strongly prefer interactions with very similar sequences, resulting in the high sequence specificity of the process of amyloid formation [23-26]. In this conformation, APRs are stapled together into $\beta$-sheets through backbone hydrogen bonds and their amino acid side chains stack laterally within the sheet and interdigitate between opposing sheets to form a tightly packed structure known as a "steric zipper" [21, 27]. This structure explains the sequence specificity of amyloid aggregation as most sequence variants would not be able to integrate with such tightly packed conformations. This unique molecular mechanism of amyloid formation results in the fact that all amyloids, formed by different aggregating proteins that bear no sequence similarity to one another, show a remarkably similar macromolecular fibril architecture.

The accumulation of over 35 proteins or peptides in welldefined amyloid states is strongly linked to human diseases [9]. Amyloid accumulation can occur in specific organs or in a systemic manner. For example, $\mathrm{A} \beta, \alpha$-synuclein, and the prion protein $(\mathrm{PrP})$ form amyloid deposits in the brain, and are associated with Alzheimer's Disease (AD), Parkinson's Disease (PD), and Creutzfeldt-Jakob Disease (CJD), respectively, while amyloid formation of islet amyloid polypeptide (IAPP) in the pancreas is associated with type 2 diabetes (T2D) [9]. Transthyretin (TTR) and $\beta 2$-microglobulin ( $\beta 2$ $\mathrm{m})$ both lead to systemic amyloidosis by forming amyloid depositions in different organs throughout the body [9]. The origin of amyloid toxicity has been a subject of debate for many years. It appears that the soluble, oligomeric amyloid species encode the predominant toxic effect, which is most pronounced in neuropathic disorders [28-30]. However, as mature amyloid fibrils can serve as a reservoir of such oligomers and in themselves also show significant toxicity, they can hardly be labeled as inert byproducts [31]. It was shown that the exposure of hydrophobic patches in the oligomeric aggregates correlates well with toxicity. This enables the oligomers to interact with a large number of molecular species, including phospholipid bilayers, protein receptors, soluble proteins, RNAs, and small metabolites [30, 32]. Amyloiddriven interference with any of these molecular pathways can eventually lead to cell death and it seems unlikely that all amyloid-associated diseases can be explained by one unique toxic event.

In addition to this toxic gain-of-function effect of amyloids, the transformation of a native protein into an aggregated state also results in a loss-of-function effect. Most amyloidogenic proteins encode cellular functions in their native state, which are lost in their amyloid form. IAPP is a peptide hormone that plays a role in glycemic regulation [33], A $\beta$ has a role in synaptic plasticity and memory [34] and $\alpha$-synuclein is important in the regulation of neurotransmission and response to cellular stress [35]. Even more, in some cases, reducing the levels of the amyloidogenic protein in disease models is sufficient to induce disease phenotypes, even in the absence of amyloid, for example for $\alpha$-synuclein 
[36], tau [37], and IAPP [38]. Such observations together with the fact that amyloid-like species encode cytotoxic effects complicate the untangling of the cause or consequence of protein aggregates in disease.

Due to their abundance in affected tissue of patients, for decades, human amyloids were mainly studied in disease context: amyloids were thought of as intrinsically toxic without any apparent function. In recent years, it was shown that (1) amyloids are not necessarily toxic [3] and (2) functional amyloids are present throughout all kingdoms of life [4]. In human tissue, for example, peptide hormones can organize into amyloids that act as a storage module in pituitary secretory granules $[39,40]$. Even in the brain, the organ most linked to amyloid-associated diseases, an RNA-binding protein, cytoplasmic polyadenylation element-binding protein (CPEB), has been shown to organize into amyloids that are important for the consolidation of memory [41-43]. The role of the amyloid form of CPEB in long-term memory is completely independent of the RNA-binding function of monomeric CPEB. In bacteria, a protein called curli forms amyloids as an important extracellular matrix in biofilms [44]. Finally, yeast-expressed proteins such as Sup35 or Ure $2 p$ have the ability to organize into amyloid as an epigenetic non-Mendelian type of inheritance [45]. It is clear that amyloids are not just pathogenic depositions that lead to disease, and that they can actually perform important cellular functions. Moreover, for some amyloid-forming proteins that were first identified as a potential toxic agent in disease, a functional role of the amyloid form of the protein has been identified. For example, TAR DNA-binding protein 43 (TDP-43) forms amyloid aggregates in the neurons of patients with amyotrophic lateral sclerosis (ALS) [46]. However, recent evidence shows that the amyloid-like oligomeric assemblies of TDP-43 perform essential functions during regeneration of skeletal muscle in mice and humans [5]. The authors showed that these functional amyloids can also induce pathological TDP-43 amyloid fibrils leading to neuromuscular disease. Therefore, it seems that, in addition to the traditional functional amyloids that solely encode a functional role without being directly linked to disease or without any obvious pathogenic effect, disease-associated amyloids such as TDP-43 can also encode important cellular functions in their amyloid form and are not solely pathogenic byproducts.

It has been suggested that many, if not all, diseaseassociated amyloids may possess such functional roles in their amyloid conformation. Unraveling the precise role of amyloids might provide a new approach to combat the associated human diseases that are linked to these amyloids. The best-studied hypothesis is based on the antimicrobial properties of disease-associated amyloids [47]. This is emphasized by numerous documentations of interactions between human-expressed amyloidogenic
Table 1 Overview of interactions between human amyloids and human-infecting viruses

\begin{tabular}{lll}
\hline Amyloid & Virus & References \\
\hline Alpha-synuclein & Influenza A & {$[50]$} \\
Alpha-synuclein & West Nile Virus & {$[51]$} \\
Amyloid beta & HSV-1 & {$[6,7,52-64]$} \\
Amyloid beta & HSV-2 & {$[65]$} \\
Amyloid beta & Varicella-zoster virus & {$[66,67]$} \\
Amyloid beta & Cytomegalovirus & {$[68]$} \\
Amyloid beta & HHV-6A and HHV-6B & {$[6]$} \\
Amyloid beta precur- & HIV & {$[69]$} \\
sor protein & & \\
Amyloid beta & Influenza & {$[70,71]$} \\
IAPP & Varicella-zoster virus & {$[72]$} \\
IAPP & Respiratory syncytial virus & {$[10]$} \\
Seminal amyloids & HIV & {$[8,73,74]$} \\
Seminal amyloids & Ebola virus & {$[75]$} \\
Seminal amyloids & Cytomegalovirus & {$[76]$} \\
Tau & HSV-1 & {$[55,77,78]$} \\
Tau & HSV-2 & {$[65]$} \\
Tau & Cytomegalovirus & {$[68]$} \\
\hline
\end{tabular}

${ }^{\text {a }}$ The interaction was shown between a short amyloidogenic fragment of IAPP and varicella-zoster virus

proteins and viruses (Table 1). Here, we review direct or indirect associations between human amyloids and humaninfecting viruses reported to date and discuss the potential underlying mechanisms together with the implications of these interactions. Noteworthy, amyloids have also been shown to associate with bacteria and fungi $[48,49]$, so, to some extent, some conclusions can be extended to the interactions between amyloids and other microbial pathogens, as well.

\section{Amyloid associations with viruses}

Almost 3 decades ago, it was suggested that a herpes simplex virus-1 (HSV-1) infection could be an important causal agent of one of the best-studied amyloid-associated diseases: Alzheimer's Disease [7, 79]. Since then, multiple direct and indirect interactions between human-expressed amyloids and viruses have been described. Some amyloids seem to exert a direct antiviral effect on human-infecting viruses, while others stimulate viral infection. Additionally, multiple amyloid-associated diseases have been shown to be clinically linked to viral infections without evidence of direct amyloid-virus interactions. A summary of the reported associations between human-expressed amyloids and human-infecting viruses is shown in Table 1. 


\section{$A \beta$ and tau interact with herpesvirus}

By far the best-studied case of an interaction between amyloids and viruses is the one of HSV-1 in Alzheimer's Disease (AD) patients [7, 52-54]. HSV-1 infects sensory neurons and via the trigeminal ganglion enters the central nervous system where it can remain in a latent state or cause acute encephalitis. It is thought that recurrent reactivation from latency over the course of years can spark the molecular mechanisms leading to $\mathrm{AD}$. The first evidence linking HSV-1 to AD originated from a striking correlation between patients carrying APOE- $\varepsilon 4$, a major genetic risk factor for $\mathrm{AD}$, and the presence of herpes DNA in the brain [53]. Reversibly, APOE- 44 was found to be a risk for cold sores, which are caused by HSV-1 [53]. A study in which 33,000 patients were monitored for 16 years showed that HSV-1 infections increase AD risk 2.5-fold [80]. Moreover, providing anti-herpetic medications reduced this risk by $\sim 90 \%$. Although the study was heavily debated [81], the results remain remarkable.

Later, evidence for direct amyloid-virus interactions accumulated. First, it was shown that HSV-1 DNA is present inside the amyloid depositions, called plaques, in the brain of deceased AD patients [55]. Moreover, $\mathrm{A} \beta$, the peptide that organizes into these amyloid plaques, accumulates in HSV-1-infected cell cultures [56-58] and in the brains of HSV-1-infected mice [56]. Eimer et al. [6] showed that the presence of HSV-1 virion particles sparks amyloid formation of $\mathrm{A} \beta$ in 5XFAD mice and 3D human neural cell culture infection models. The authors showed that this amyloid seeding reaction was initiated by a direct interaction with the viral surface glycoproteins [6].

In addition to the direct interaction between $\mathrm{A} \beta$ and HSV1 , tau, the protein that forms amyloidogenic neurofibrillary tangles in AD brain, also accumulates in HSV-1-infected cell cultures $[55,77,78]$. More recently, it was shown that the herpes infections directly lead to an up-regulation of $A \beta$ and tau and that the amyloidogenic form of $A \beta$ actually encodes antiviral properties and directly 'attacks' virion particles $[6$, 59-62]. Interestingly, treatment with various types of antivirals such as acyclovir has been found to decrease the level of $\mathrm{A} \beta$ and, particularly, that of amyloidogenic phosphorylated tau [63].

In addition to HSV-1, multiple other viruses from the Herpesviridae family have been associated with AD. Herpes simplex virus-2 (HSV-2) infection was shown to induce AD-like neurodegeneration markers, including accumulation of hyperphosphorylated tau and $A \beta$ [65]. Varicella-zoster virus (VZV) infection leads to an increased risk of $\mathrm{AD}$ by almost threefold [66, 67]. Cytomegalovirus (CMV) induces production of $A \beta$ in cell culture and CMV serum IgG antibody levels correlate strongly with tau tangles in AD patients [68]. Human betaherpesvirus 6A (HHV-6A) and 6B (HHV-6B) RNA levels are increased in $\mathrm{AD}$ brain regions, and show a correlation with amyloid plaque load and tau tangle levels. Moreover, $\mathrm{A} \beta$ was shown to directly bind to HHV-6A and HHV-6B surface proteins and induce amyloid formation [6].

\section{$A \beta$ interacts with human immunodeficiency virus}

Since the successful introduction of retroviral therapies, other conditions emerged in human immunodeficiency virus (HIV)-infected patients, mainly diseases that are associated with aging, altogether named HIV-1-associated neurocognitive disorders (HAND) [82, 83]. Amyloid plaques, reminiscent of the ones observed in AD patients, are detected in the brains of patients suffering from HAND. Moreover, it was established that HIV infection can directly lead to increased production of $A \beta$. It was proposed that the $A \beta$ precursor protein (APP) may act as an innate restriction peptide that inhibits replication of HIV by sequestering the HIV Gag polyprotein in lipid rafts to block the production and spread of HIV [69]. Indeed, as most of these patients were successfully treated with retroviral therapies, limited HIV outbreaks are present. As such, the amyloid depositions found in these patients are most likely the result of direct or indirect interactions with viral proteins (e.g., Tat and Gag) instead of complete virion particles.

\section{$A \beta$ interacts with influenza virus}

The antiviral nature of the amyloidogenic $\mathrm{A} \beta$ peptide has also been shown against influenza. In vitro, it was shown that $A \beta$ inhibits replication of seasonal and pandemic strains of $\mathrm{H} 3 \mathrm{~N} 2$ and $\mathrm{H} 1 \mathrm{~N} 1$ influenza $\mathrm{A}$ virus [70]. $\mathrm{A} \beta$ exerts its antiviral effect by inducing virion particle aggregation, thereby reducing the infection rate of this virus. The same group later showed that the C-terminal amyloidogenic fragment of $A \beta$ is responsible for the antiviral effect against influenza A viruses [71].

\section{IAPP interacts with varicella-zoster virus}

Amyloids formed by the short islet amyloid polypeptide (IAPP) in the pancreas is associated with type 2 diabetes (T2D). VZV-infected cells induce intracellular IAPP amyloid formation and the supernatant from VZV-infected cells induced IAPP aggregation. Interestingly, VZV glycoprotein $\mathrm{B}(\mathrm{gB})$-derived peptides assembled into fibrils and were able to catalyze IAPP aggregation as well as $A \beta-42$ aggregation [72]. The latter indicates that amyloid-specific seeding events might catalyze the interaction between a viral protein and an amyloidogenic peptide. 


\section{An IAPP peptide interacts with respiratory syncytial virus}

Respiratory syncytial virus (RSV) accelerates aggregation of an IAPP-derived peptide (NNFGAIL) and this seeding effect is specific as RSV does not have an effect on the aggregation of another amyloidogenic peptide [10]. In this case, the direct interaction between an IAPP-derived peptide and RSV virion particles seems to be driven by a specific interaction instead of a specific clustering of the amyloidogenic peptide on the viral surface.

\section{a-Synuclein interacts with influenza}

A controversial association is the one between influenza infections and $\alpha$-synuclein, a protein that organizes into amyloid and deposits in dopaminergic neurons in synucleinopathies, including Parkinson's Disease (PD). The association was first reported when postencephalitic parkinsonism appeared following the influenza pandemic of 1918-1920, also known as the Spanish flu [84, 85]. Other groups have since then also reported influenza infections as a risk factor for PD [86]. Although the possible association between influenza infections and PD is still a matter of debate, Marreiros et al. [50] have recently shown that acute H1N1 infection leads to the formation of $\alpha$-synuclein aggregates in dopaminergic neurons. The authors showed that $\alpha$-synuclein aggregates were induced in infected neurons connected to the olfactory bulb following intranasal infection in mice. Moreover, this $\alpha$-synuclein seeding event is amyloid-specific, as no effect was observed on two additional aggregation-prone proteins: tau or TDP-43. Whether or not an influenza infection is a risk factor for PD, this study shows a direct association between infection and $\alpha$-synuclein amyloid depositions, one of the major hallmarks of PD and other synucleinopathies.

\section{a-synuclein interacts with West Nile virus}

Parkinsonism has been linked with West Nile virus (WNV) infection almost 2 decades ago [87, 88]; however, a clear association between $\alpha$-synuclein and WNV is currently lacking. Interestingly, Beatman et al. [51] did show that $\alpha$-synuclein inhibits WNV infection. By performing a peripheral WNV infection in $\alpha$-synuclein knock-out mice, the authors observed an increased sensitivity to viral infection. Viral growth in the $\alpha$-synuclein knock-out mouse brain was increased compared to wild-type mice. The authors hypothesized that $\alpha$-synuclein inhibits peripheralto-central nervous system transportation, thereby strongly reducing viral infection in the brain. They also showed that $\alpha$-synuclein colocalizes with an WNV envelope protein, hinting at a direct interaction between the two.

\section{Semen-derived amyloids stimulate virus infection}

Over a decade ago, it was demonstrated that semen harbors amyloid fibrils that drastically enhance HIV infection [8]. Currently, three different proteins are identified that can generate amyloids able to stimulate viral infection: prostatic acidic phosphatase (PAP), semenogelin-1 (SEM1), and semenogelin-2 (SEM2) [73]. In fact, it is not the full protein but rather short peptide fragments originating from these precursor proteins that organize into amyloid structures. The amyloid formed by a naturally occurring peptide comprised of residues 248-286 from PAP was found to boost the infectious titer of HIV-1 by more than five orders of magnitude, and the fibrils formed by this peptide were termed SEVI, for Semen-derived Enhancer of Viral Infection [8]. It is important to mention that the seminal amyloids are detected in HIV-1-infected as well as healthy individuals [74]. Importantly, the promoting effect observed for SEVI for enhanced HIV infection is amyloid-specific, as other amyloids, for examples those formed by the bacterial curli proteins (Csg A and CgsB) do not increase HIV infectivity [89].

In addition to HIV, other viruses can also be affected by seminal amyloids. For example, Ebola virus infection is greatly enhanced by seminal amyloids by physical interaction between the two [75]. The amyloids were able to increase viral infectivity and enhance viral stability after extended incubation at increased temperature.

Finally, in vitro experiments showed that both human and murine CMV infection was strongly enhanced by seminal amyloid in cell culture [76]. Seminal amyloids increased infection rates by more than tenfold, while replication was increased up to 100-fold. The authors showed that a physical interaction between the amyloids and the glycoproteins on the surface CMV virion particles causes this effect [76].

\section{Clinical associations between amyloid-associated diseases and viral infections might point to additional amyloid-virus interactions}

An association between type 2 diabetes (T2D) and a hepatitis C virus infection was first described in 1994 [90]. The study showed that in a population of cirrhotic patients, the ones exposed to hepatitis $\mathrm{C}$ have a significant higher chance of developing T2D. In the following years, this association was confirmed by other groups and moreover was shown to be a virus-specific observation as hepatitis B virus or other forms of chronic liver disease infection did not associate with T2D [91-93]. Interestingly, this association seems to be bidirectional as T2D patients seem to be more prone to acquire hepatitis C infections [94-96]. Whether or not there is indeed a causative relation between hepatitis $\mathrm{C}$ infection and T2D remains to be studied, but deposition of amyloidogenic IAPP is one of the major T2D hallmarks. 
Numerous different studies showed correlations between PD symptom development and infection by a certain viral strain, including influenza, West Nile virus, hepatitis C, Japanese encephalitis virus, St. Louis encephalitis virus, coxsackievirus, and Western equine encephalitis virus [88, 97-101]. Most of these did not show direct interactions between viruses and the amyloid form of $\alpha$-synuclein; however, Bantle et al. [101] recently showed that a neuroinvasive infection of Western equine encephalitis virus (WEEV) induces $\alpha$-synuclein aggregation in different areas of a mouse brain.

Recently, an analysis of postmortem brain tissue showed a strong correlation between the presence of capsid protein 1 from Ljungan virus (LV), a picornavirus, in neurons and astrocytes, and the development of AD [102]. Moreover, the same authors published a case report in which a small number of patients showed improved or unchanged cognitive function when treated with three different antivirals [102].

\section{Mechanistic insights into amyloid-virus interactions}

Many direct and indirect interactions between humanexpressed amyloids and human-infecting viruses have been described today (Table 1). However, relatively little research has been performed to unravel the underlying molecular mechanisms of these interactions. To understand the potential mechanisms of amyloid-virus interactions, it is important to describe how the amyloid aggregation reaction initiates.

In its most simple representation, the amyloid reaction can be described as a two-step process [103]. First, an aggregation nucleus or seed is formed, which is the rate-limiting step of the amyloid reaction. Starting from this nucleus, a growth reaction follows in which new monomeric units of a protein are added to the amyloid chain. This two-step nucleation-growth process translates into the typical sigmoidal aggregation reaction including a lag phase (nucleation) and an exponential phase (growth). Hidden in the lag phase, the kinetic description of amyloid aggregation also includes the thermodynamic limitation of nucleus formation: the transition from monomers to an aggregation seed is thermodynamically unfavorable and is therefore a rare event. Providing a preformed aggregate (seed) can promote the aggregation reaction significantly, a mechanism referred to as aggregation seeding. In addition to seeding, other aggregation nucleation events have been described, mainly surface-catalyzed nucleation. To summarize, the amyloid aggregation reaction can be initiated spontaneously or via a catalyzed nucleation event (Fig. 1). These nucleation events can be driven by surfaces in a non-specific manner or by the addition of preformed aggregates (seeding) encoding sequence specificity into the interaction $[9,104]$.

These three events of amyloid initiation (spontaneous nucleation, surface-catalyzed nucleation (SCN), and sequence-specific seed nucleation $(\mathrm{SN})]$ translate into three non-mutually exclusive hypotheses that have been described to explain amyloid-virus interactions. First, it is possible that viral infections indirectly lead to accumulation and aggregation of amyloidogenic proteins, for example by interfering with degradation pathways of these proteins. Second, some evidence shows that the presence of virion particles might directly spark amyloid formation by surface-catalyzed nucleation. Third, in some cases, sequence-specific amyloid interactions can drive the binding of amyloidogenic proteins or peptides to viral proteins. Here, we summarize the evidence for each of these potential mechanisms underlying amyloid-virus interactions (Fig. 1).

1. Viral infections can indirectly promote spontaneous amyloid nucleation

There are a few events that can lead to spontaneous aggregation, meaning without the addition of a catalyst to initiate the aggregation reaction. First, aggregation-stimulating mutations can include mutations that facilitate spontaneous nucleus formation $[105,106]$ or complete gene multiplications leading to increased protein levels [107-109]. Second, events leading to an increased local concentration can significantly reduce the nucleation barrier, a prime example being liquid-liquid-phase separation [110]. Third, deterioration of the cellular quality control systems such as chaperones, for example as a result of aging, can lead to increased accumulation of misfolded proteins, also lowering the nucleation barrier for aggregation [111].

In some cases, the latter event has been described to be the driving force of virus-induced amyloid accumulation. For the best-studied case of an amyloid-virus interaction, the association between $A \beta$ and herpesvirus infection, it has been proposed that the dysregulation of autophagy might play an essential role. Herpesviruses interfere with autophagy pathways to optimize their replication and to counteract immune response during primary infection, but also during reactivation from latency [112-117]. For example, gamma herpesviruses block the final steps of autophagy during the lytic cycle for transportation to the membrane [118, 119]. Both HSV-1 and HHV-6B are able to block autophagy in infected neurons and peripheral blood cells, respectively $[116,117,120]$. Remarkably, two other herpesviruses, varicella-zoster virus and HHV-6A, have the opposite effect and promote autophagy to prolong the survival of infected cells [117, 121, 122]. It is well established that cells strongly depend on protein quality control systems to maintain homeostasis. Autophagy is such a mechanism that 

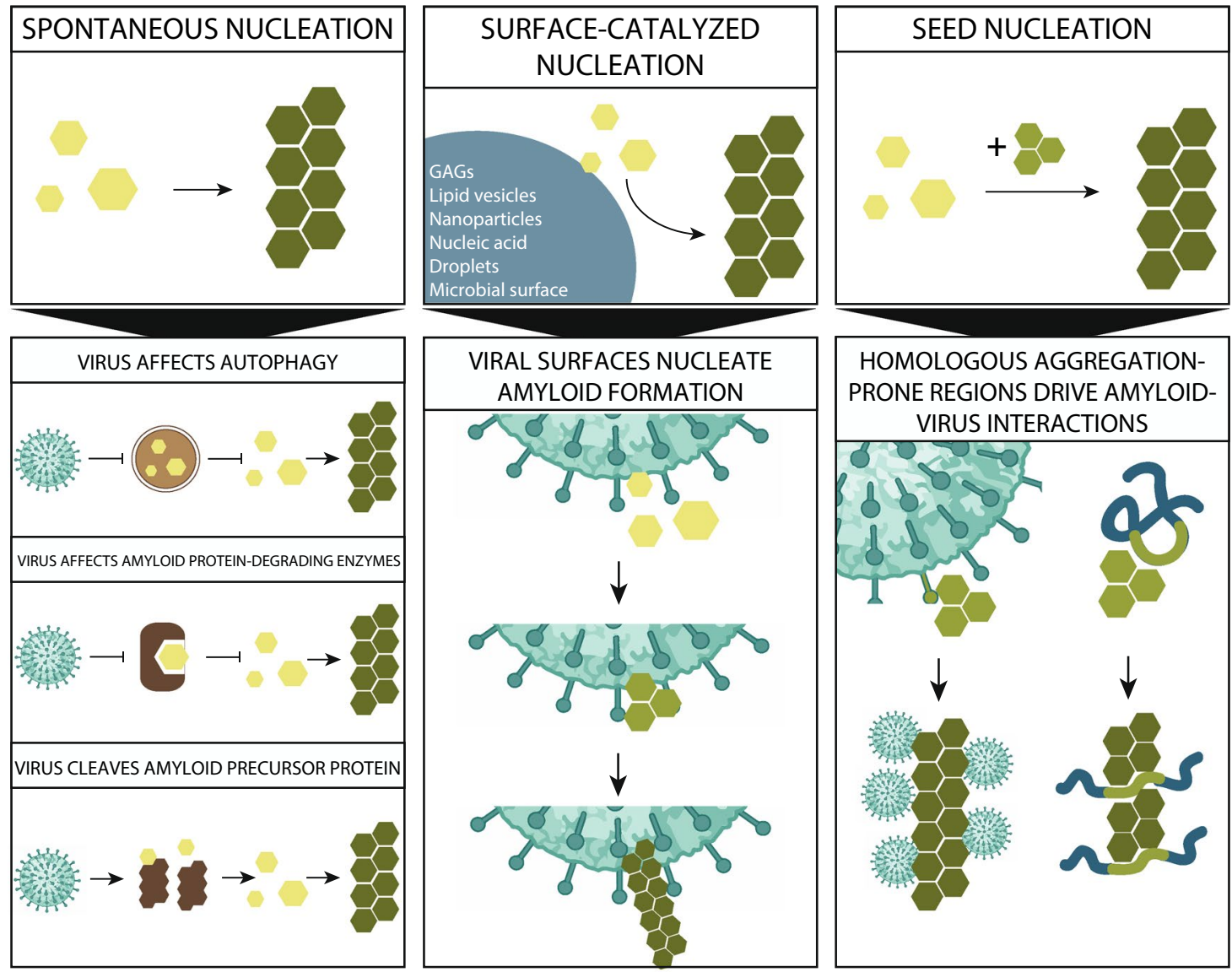

PRONE REGIONS DRIVE AMYLOID-
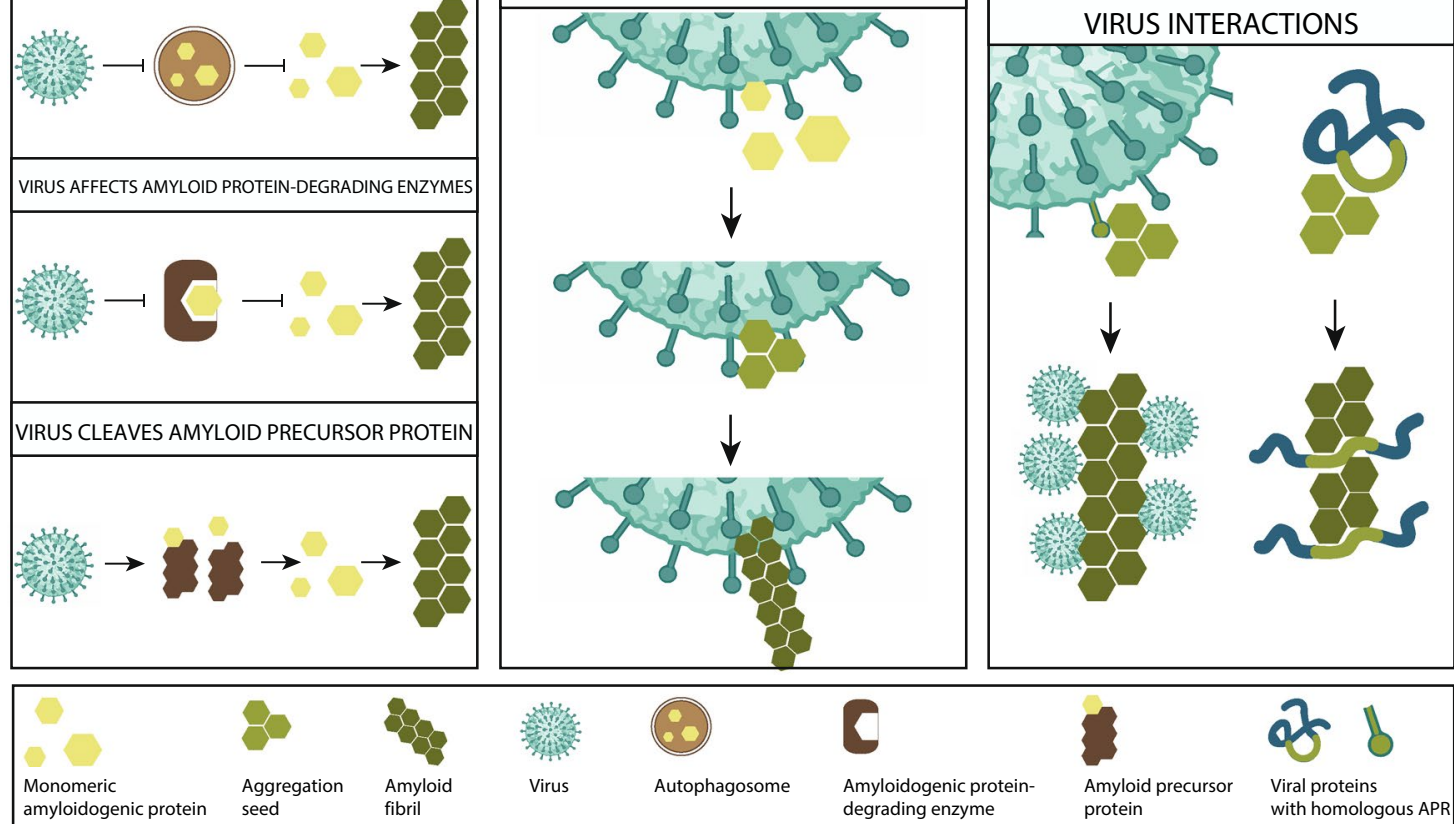

Fig. 1 A schematic overview of the mechanisms underlying amyloidvirus interactions. The three upper panels represent three different mechanisms by which amyloid formation can initiate: spontaneous

is used to remove toxic components such as misfolded proteins and protein aggregates, which is especially important for post-mitotic cells like neurons. Shutting down autophagy leads to neurodegeneration and increased neuronal cell death in neurons [123]. One of the characteristics of Alzheimer's disease is an increased number of autophagosomes in the neurons, suggesting a dysregulation of autophagy [124]. Moreover, aging, one of the most relevant risk factors for amyloid-associated neurodegenerative diseases, is usually accompanied by a progressive reduction of autophagy [125]. More specifically, autophagy is a crucial process in the metabolism of multiple amyloids themselves, including $A \beta[126]$ and tau protein [127]. For example, an autophagydeficient mouse model showed increased $A \beta$ accumulation and induced neurodegeneration [128]. Altogether, the fact that neurons strongly depend on autophagy and autophagy is involved in the metabolism of the amyloidogenic proteins nucleation, surface-catalyzed nucleation ( $\mathrm{SCN})$, and seed nucleation (SN). Each of these three mechanisms translates into a different process of amyloid-virus interactions, which are non-mutually exclusive

(A $\beta$ and tau) together with the observation that herpesviruses dysregulate autophagic pathways could indeed suggest a possible indirect link between herpesvirus infection and amyloid-associated pathology in AD.

Additional evidence linking autophagy dysregulation to amyloid-virus interactions resulted from the HIV-A $\beta$ association. It was shown that Tat, the HIV trans-activator of transcription protein, interferes with endolysosome formation [129]. In neurons, Tat induces endolysosome enlargement and disturbs endolysosome function. Additionally, it was shown that intraneuronal $A \beta$ is significantly increased in patients suffering from HIV encephalitis, particularly in autophagosomes [130]. Altogether, these data suggest that the HIV Tat protein might impair endolysosome function and thereby interfere with the proper clearance of $A \beta$ [130].

Also, for the $\alpha$-synuclein-influenza case, an indirect mechanism affecting autophagy could be the driving force 
of interaction. Marreiros et al. [50] showed that H1N1 influenza A viral infection and replication leads to a disturbance in protein homeostasis by inhibiting autophagosome-lysosome fusion. The authors show that this leads to impaired $\alpha$-synuclein degradation and eventually depositions of $\alpha$-synuclein amyloid.

In addition to the autophagy-mediating effect of viruses, HSV-1 can also influence other upstream events that eventually lead to $\mathrm{A} \beta$ and tau amyloid deposition. For example, Civitelli et al. [131] showed that HSV-1 infection in neurons leads to accumulation of APP intracellular domain (AICD), eventually affecting expression levels of NEP and GSK3 $\beta$. Nep is a major $A \beta$-degrading enzyme $[132,133]$, while GSK3 $\beta$ is a serine/threonine kinase that promotes hyperphosphorylation of tau and the increased $\mathrm{A} \beta$ production [134]. In this way, HSV-1 could modulate amyloid deposition in an indirect manner.

The HIV Tat protein can also modulate $A \beta$ expression indirectly independent of autophagy [135]. It was shown that HIV infection leads to hypoxia-inducible factor (HIF-1 $\alpha$ ) up-regulation followed by its binding and inactivation to the long noncoding RNA (lncRNA) BACE1-antisense transcript (BACE1-AS). The latter has been shown to promote the stability of the (sense) BACE1 transcript [136], leading to increased BACE1 levels, the protein responsible for toxic $\mathrm{A} \beta$ generation.

Zheng et al. [137] identified an HSV-1-encoded microRNA (miR-H1) that is able to reduce the expression and activity of Ubr1, an RING-type E3 ubiquitin ligase that mediates $\mathrm{A} \beta$ degradation. In this way, HSV-1 infection can indirectly lead to the accumulation of $A \beta$ amyloid deposits.

Finally, as mentioned before, Chai et al. showed a direct interaction between the HIV-1 Gag polyprotein and the A $\beta$ precursor protein (APP). Although it is a direct interaction, we prefer to describe it in this section as it was only established as an interaction between one viral protein (not the virion particle) and the precursor protein of $A \beta$ (not the amyloid peptide itself). The authors showed that APP acts as an innate antiviral peptide by sequestering the HIV Gag polyprotein in lipid rafts, in this way blocking further HIV replication [69]. Remarkably, the Gag polyprotein promotes cleavage of APP to escape this antiviral effect of the A $\beta$ precursor protein. This leads to an increased production of the toxic and amyloidogenic $A \beta$ peptide. The authors showed that, as a result of $A \beta$ amyloid formation, primary cortical neurons degenerated, an event that could be prevented by $\gamma$-secretase inhibitor treatment.

The evidence described here suggests that upon viral infection, multiple cellular pathways that are associated with amyloid formation or clearance can be disrupted, in this way indirectly affecting amyloid accumulation. However, the opposing effects of some viruses (e.g., HHV-6A promotes, while HHV-6B inhibits autophagy) complicate the understanding of how multiple infections result in similar clinical effects. Thus, although an indirect effect of a viral infection can be the initial spark towards up-regulation of the amyloidogenic protein, most of the evidence described today points towards a direct binding of an amyloid to a viral surface or specific viral protein. As mentioned before, the amyloid aggregation reaction is usually initiated by a catalyzed nucleation mechanism. These can roughly be divided into surface-catalyzed nucleation ( $\mathrm{SCN}$ ) or sequence-specific seed nucleation ( $\mathrm{SN}$ ), and can each explain a direct interaction between amyloids and viruses.

2. Viral surfaces can catalyze amyloid nucleation

It has been known for a while that exogenous surfaces are able to catalyze the amyloid nucleation process, a mechanism referred to as surface-catalyzed nucleation (SCN) [138]. During SCN, a certain surface can increase the local concentration and enables conformational changes necessary to induce the amyloid reaction. Many different surfaces have been shown to lower the energy barrier for amyloid nucleation, including microbial surfaces [10, 101], lipid vesicles [139, 140], nanoparticles [141], glycosaminoglycans (GAGs) [142, 143], nucleic acids [144] and even the surface of a liquid-liquid-phase separation droplet [145]. A special case of SCN is secondary nucleation, in which the surface of a preformed aggregate, instead of the reactive ends, serves as a catalytic spot for amyloid initiation [146].

Recently, a few studies point towards SCN as a crucial factor in virus-induced amyloid depositions. Starting with the best-studied case of the $A \beta$-herpesvirus interaction, colocalization of HSV-1 DNA in amyloid plaques was a first indication of a direct interaction between the two. In 2015, Bourgade et al. [60] showed that A $\beta$ inhibits HSV-1 replication by a direct binding event to its surface glycoproteins. Moreover, they showed that $A \beta$ only exhibits this antiviral effect when the amyloid is added before the virus, indicating a direct extracellular event on the virion particle. Indeed, $\mathrm{A} \beta$ did not affect the replication of a non-enveloped human adenovirus and the antiviral effect was removed by simply washing away the extracellular $A \beta$.

Building on these findings, Eimer et al. [6] showed that this binding event of $A \beta$ oligomers onto the surface of HSV- 1 particles induces A $\beta$ fibril formation. This event accelerated $\mathrm{A} \beta$ plaque formation in 5XFAD transgenic mice and at the same time protected those mice from a harmful HSV-1 infection. Of note, the authors showed the same effect for two other herpesviruses (HHV-6A and HHV-6B) in a $3 \mathrm{D}$ human neural cell culture infection model. The authors attributed this effect to SCN on microbial surfaces. They show that the seeding propensity of virion particles is 1-2 orders of magnitude more rapid than reported for $A \beta$ fibrilization mediated by host glycosaminoglycans. They 
hypothesize that microbial sugars, rather than host glycosaminoglycans, are the actual target of $\mathrm{A} \beta$ oligomers.

Ezzat et al. [10] performed a more unbiased analysis of the proteins binding to the surfaces of RSV and HSV-1, termed the viral protein corona. Interestingly, they show that each virus composes a unique protein corona and that the specific protein layer determines the infectivity of the virus. More specifically, they showed that amyloidogenic peptides including IAPP and A $\beta$ were able to bind the surface of RSV and HSV-1, respectively. Even more, the virion particles were able to nucleate the amyloid formation of both peptides in vitro and in animal models, confirming the observations made by Eimer et al. [6].

In addition to the HSV- 1 case, it was also shown that $\mathrm{A} \beta$ can induce the aggregation of influenza $\mathrm{A}$ virion particles by physical interactions [70], indicating that a similar mechanism is at play in this case.

Another direct interaction between virion particles and amyloids was observed between HIV and SEVI amyloids [8]. Amyloids formed by a short peptide derived from PAP are present in the semen of healthy individuals [74] and upon HIV infection bind to the virion surface. This binding event, driven by the cationic properties of the fibrils, drastically enhances virion attachment to and fusion with target cells [147]. Removing the positive charges, but maintaining the amyloid propensity, did abolish the promoting effect on viral infectivity. The latter suggests that the positively charged amyloid fibrils allow the viruses to come into close proximity to the negatively charged host membrane and in this way facilitate infection. This was confirmed by the fact that the infection enhancing effect was not observed for $A \beta$ fibrils. However, $A \beta$ fibrils have been shown to bind negatively charged phospholipid membranes [148]. Additional amyloids, for example those formed by the bacterial curli proteins (Csg A and CgsB), also do not increase HIV infectivity [89]. Interestingly, an HIV gp120-derived peptide produced from the natural degradation in gp120-loaded rat hepatocytes induced the aggregation of SEVI [149]. This finding suggests that although SEVI amyloid is present in healthy individuals, HIV virion particles might boost the stimulation of increased SEVI amyloid levels to increase its own infectivity. Later, Chen et al. [150] showed that the gp120-derived peptide can also self-assemble into amyloid fibrils and enhance HIV infectivity without SEVI.

For the association between HIV and $A \beta$, a very specific interaction effect has been described [151]. Using in vitro studies, the authors showed that when the HIV Tat protein was added to preformed $\mathrm{A} \beta$ amyloid fibrils, these fibrils matured into thicker, unstructured fibrils. This lateral reorganization resulted in fibrils with increased rigidity and mechanical resistance. Moreover, Tat protein and $A \beta$ exerted a synergistic neurotoxic effect both in vitro and in vivo. The authors hypothesized that the reorganized fibrils may account for increased neuronal damage due to increased potential to form transmembrane pores.

3. Sequence-specific nucleation can drive amyloid-virus interactions

In contrast to $\mathrm{SCN}$, the best-studied case of aggregation seeding is homologous seeding: a preformed aggregate (seed) of the same protein can act as a template to initiate the aggregation of more monomeric protein. Almost two decades ago, it was shown that these aggregation seeding reactions strongly depend on similarity of their sequences: preformed aggregates most efficiently induce the aggregation of proteins encoding high sequence similarity, a process referred to as homologous seeding [23-26]. This sequence dependence originates from the underlying molecular structure of amyloid aggregates: the tight packing does not easily allow sequence mismatches in the core. However, on multiple occasions, it has been shown that incorporation of sequences that are only slightly different can still fit into the cross- $\beta$ steric zipper [25] and this is referred to as heterotypic interactions (or cross-seeding).

Some of the amyloid-virus interactions that have been described so far point to a sequence-specific amyloid interaction. If a certain amyloidogenic peptide shares a homologous amino acid stretch with a viral protein, this allows the initial interaction between the two that sparks the amyloid fibrillation reaction. More specifically, if viral surface proteins encode such homologous stretches to amyloid-prone peptides, some of the interactions that are now thought of as surface-induced could potentially have a sequence-specific driving force. Already $2 \mathrm{dec}-$ ades ago, it was pointed out that the glycoprotein $\mathrm{B}(\mathrm{gB})$ of HSV- 1 shares a homologous region with $A \beta$, with the highest degree of similarity located at the N-terminal amyloidogenic region of $A \beta$ (Fig. 2) [152]. Even earlier, it was suggested that the same region of $\mathrm{gB}$ is responsible for neurotoxicity [153] and fibril formation [154]. In the study published by Eimer et al. [6], the importance of this viral glycoprotein was highlighted by the fact that the interaction between HSV- 1 and A $\beta$ could be inhibited by blocking these viral surface proteins. Moreover, a scrambled version of $A \beta$ did not interact with virion particles, highlighting the potential sequence specificity of this interaction $[6$, $60]$.

Glycoprotein B is not the only surface protein that shares a homologous sequence to $A \beta$ : a 28 -residue-long peptide derived from $\mathrm{HSV}-1$ glycoprotein $\mathrm{K}(\mathrm{gK})$ organizes into amyloid fibrils and shares a very similar region with a sixamino acid stretch in the $\mathrm{N}$-terminal amyloidogenic region of $A \beta$ (gK, VGLIVG; $A \beta$, IGLMVG). Interestingly, this peptide is expected to result from cleavage by the human $20 \mathrm{~S}$ proteasome [155]. 

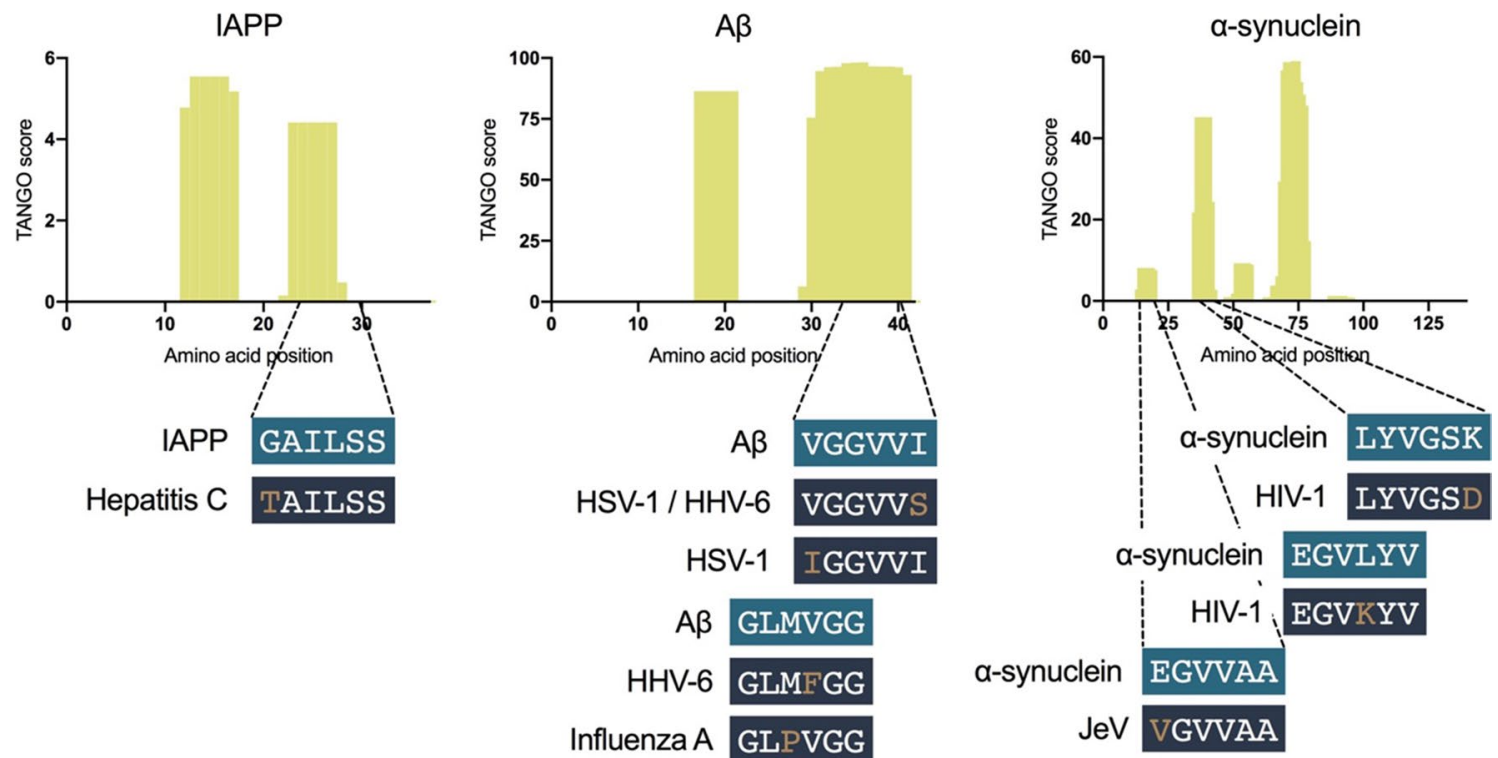

Fig. 2 Human-expressed amyloids share homologous APRs with viral proteins. The graphs represent TANGO analyses to identify APRs in the amyloids [17]. The TANGO score is a value between 0 and 100 and higher scores represent higher aggregation potential of the amino acid sequence. As such, the yellow bars represent the

Looking back at the study performed by Ezzat et al. [10], both RSV and HSV-1 compiled a unique protein corona on their surface and remarkably, both viruses induced the aggregation of unique amyloidogenic fragments. For example, RSV induced the amyloid fibrillation of an IAPP peptide. This seeding event was abolished by pre-incubation of the virion particles in a $5 \%$ serum solution, indicating that a physical interaction with the virion surface or specific viral surface proteins is crucial to induce amyloid fibrillation. Of pivotal importance, however, is the fact that another amyloidogenic peptide (GNNQQNY), derived from the yeast Sup35 prion protein, was not seeded by the same virion particles in identical conditions. The latter indicates that sequence-specific interactions might underlie the initial binding between amyloidogenic peptides and viral surface proteins. This study, however, also indicates that the amyloid-interacting protein on the viral surface is not necessarily a viral protein, as viruses sequester a unique and diverse host protein corona. Even though RSV primarily infects the respiratory system, RSV virion particles have been detected in human myocardial tissue, liver, and cerebrospinal fluid [156], where it could physically interact with IAPP, a peptide hormone. Of note, Ezzat et al. also confirmed previous findings that HSV-1 virion particles seed the amyloid aggregation of $A \beta$.

In the case of the IAPP-VZV interaction, it was shown that VZV-infected cells show an increased intracellular IAPP amyloid load. Moreover, the supernatant from
APRs of the amyloids. Below each graph, amyloid hexamer APR sequences are visualized that share a homologous fragment within a viral protein. Only homologous sequences with one amino acid mismatch are shown

VZV-infected cells induced IAPP aggregation. It was shown that preformed seeds formed by peptides derived from VZV glycoprotein B could induce IAPP aggregation [72]. The latter is an example of a typical amyloid seeding event and could explain the induced IAPP aggregation upon VZV infection.

Also for the HIV case, homologous sequence segments with $A \beta$ have been described. It was shown that a region from the HIV gp120 protein (residues 24-28 in a typical V3 loop, GAIIG) self-assembles into amyloid fibrils [157] and shares an identical stretch with $A \beta$. Importantly, no interaction studies between the two fragments were performed in this study.

Therefore, it is possible that at least for some cases, the interaction between amyloids and viruses is driven by homologous sequences that induce an amyloid-like interaction. Moreover, such interactions are not limited to the viral surface, as is the case for viral surface-catalyzed nucleation, but can also include interactions between amyloids and viral non-surface proteins. For example, regarding the known interaction between influenza $A$ virion particles and $A \beta$ [70], it was shown that the $C$-terminal fragment of $A \beta$ is the driving force [71]. This amyloidogenic $\mathrm{C}$-terminal fragment of $\mathrm{A} \beta$ shares a homologous region with a viral non-surface protein, the RNA-directed RNA polymerase (Fig. 2). Physical interactions between the amyloidogenic peptide and the viral protein would then be possible inside the virion particle or inside the infected host cell. 
Figure 2 visualizes homologous APRs sequences between human amyloids and viral proteins. Whether or not such homologous sequences drive their interaction and a subsequent amyloid seeding event remains to be studied, but the presence of this sequence similarity at least shows the possibility of a co-evolution event. Amyloids could have evolved as a natural defense mechanism to protect against the acute threat of a viral infection. Their subsequent accumulation in human tissue could then be an unwanted side-effect of their antimicrobial activity and usually only causes problems years after aggregation initiation.

\section{Therapeutic potential}

These data indicate that homologous aggregation-prone regions between an amyloidogenic peptide and a viral protein can drive their interaction. We recently developed a fully synthetic amyloid that allows a specific interaction with an influenza polymerase protein: polymerase basic protein 2 (PB2) [158]. The synthetic peptide is not related to $\mathrm{A} \beta$ or any other human-expressed amyloid, but shares a homologous fragment with PB2. We have shown that this synthetic peptide organizes into amyloid-like structures, enters infected host cells, specifically binds to the influenza A PB2 protein, and induces its aggregation (Fig. 3). The interaction between the synthetic amyloid and PB2 is driven by their homologous fragment, as no interaction is observed between the influenza B PB2 protein, which lacks that fragment, or between a mutated synthetic amyloid and the influenza A PB2 protein (Fig. 3c). The latter is a crucial observation, since the synthetic amyloids should also not induce the aggregation of any host proteins. The sequence specificity of aggregation seeding reactions as described earlier allows to specifically target viral proteins if a similar amino acid stretch is not present in the host proteome. The induced aggregation of the influenza A PB2 proteins leads to a reduction of viral replication and as such the amyloid exerts an antiviral effect. As a similar antiviral effect was observed when the amyloid was added before or after viral infection, and pre-incubation of the virion particles with the amyloid did not increase the efficacy, this suggests that the amyloid-viral protein interaction occurs inside the infected host cell. This finding was confirmed by the colocalisation of the synthetic amyloid and the PB2 target protein in the cytoplasm of infected cells (Fig. 3d). Moreover, the synthetic amyloid accumulated only in influenza A-infected tissue in vivo, while no amyloid deposition was observed in non-infected tissue.

The same approach was used to design a second, unrelated amyloid that specifically binds to a Zika virus surface protein: membrane glycoprotein $\mathrm{M}$. This synthetic amyloid showed specific antiviral activity on Zika virus particles. and proved that this approach can be used to target both surface and non-surface viral proteins [158].

Zhang et al. recently showed that such approach can also be used as a detection tool for viral infections [159]. The authors designed a short amyloid-forming peptide, whose sequence is based on an aggregation-prone region identified in an SARS-CoV protein, S-protein. This amyloidogenic peptide is able to bind to the S-protein via the homologous region and, in this way, can be used as
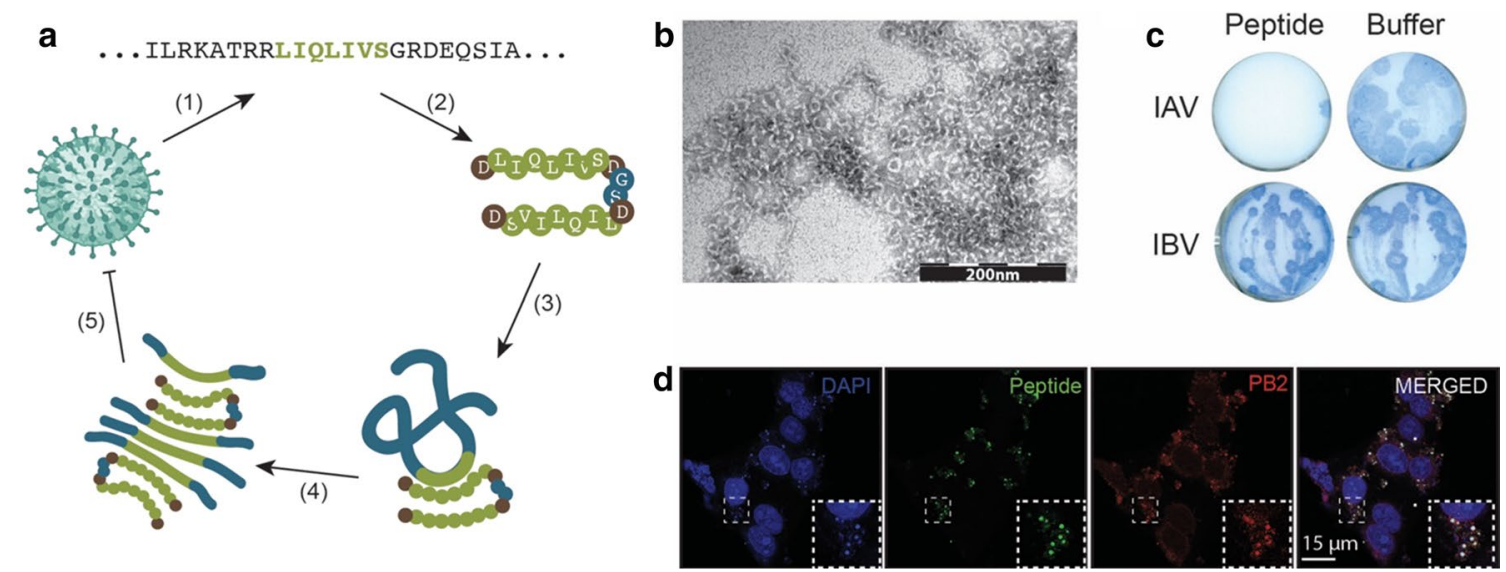

Fig. 3 Design of synthetic antiviral amyloids solely based on homologous APRs. (a) A schematic overview of the design principle of synthetic antiviral amyloids: (1) APRs are identified in the proteome of a specific virus (here: LIQLIVS from the influenza A/PR8 PB2 protein), (2) peptides are designed based on this APR sequence in a tandem design format to stimulate amyloid formation, (3) this synthetic amyloidogenic peptide can interact with the viral target protein via the homologous APR sequence, (4) which leads to the aggrega- tion and inactivation of that protein, and (5) finally reducing viral replication. b Incubating the peptide visualized in a for $1 \mathrm{~h}$ at $100 \mu \mathrm{M}$ results in amyloid-like structures. c A plaque-size reduction assays showing that the amyloidogenic peptide $(10 \mu \mathrm{M})$ inhibits influenza A (IAV) replication (blue area), while influenza B (IBV) is not affected. d Colocalisation of a fluorescent variant of the amyloidogenic peptide $(10 \mu \mathrm{M})$ and PB2 in influenza A-infected MDCK cells. All data were taken and adjusted with permission from [158] 
a highly specific detection tool for SARS-CoV infection [159].

The data described here show that the self-assembling properties of amyloidogenic peptides can be used as biochemical or therapeutic tool. Moreover, as in some cases of naturally occurring amyloid-virus interactions, such similar amino acid stretches are indeed present, it is possible that they are as well regulated by the same underlying mechanism that drives amyloid reactions. Such interactions are not limited to viral surface proteins as amyloid interactions can occur inside the infected host cell.

\section{Conclusions}

About 35 peptides and proteins are known to organize into amyloid that are associated with human diseases and it is estimated that protein aggregation affects some 500 million people worldwide $[9,160]$. Intensive research has shed some light on the molecular mechanisms underlying amyloid formation; however, a comprehensive understanding of their initiation and toxicity in disease remains incomplete. It has been shown that multiple (disease-associated) amyloids encode important cellular functions [4, 5], including as part of the host's innate immunity against microbial pathogens. Indeed, multiple amyloids have been shown to reduce viral replication in vitro and in vivo $[6,69,70]$, both indirectly, via autophagy or interference with specific host protein expression levels, and directly, via binding to viral (surface) proteins. It has been proposed that cells evolved to express amyloidogenic peptides or proteins as a first line of defense mechanism to reduce the acute treatment of a viral infection. A viral infection could then be the initial trigger for amyloid accumulation, which leads to the pathogenic side-effects, usually, decades after amyloid accumulation initiated. However, it must be mentioned that although viral infections are common in many amyloid-associated diseases, amyloid formation in these diseases can also be sparked by other phenomena, including mutations or deterioration of the PQC system as a result of aging.

Crucially, this antiviral effect of amyloids is not universal as semen-derived amyloids seem to exert the exact opposite effect: they stimulate HIV and Ebola infections. It is important to note that, in this case, the amyloids are also present in healthy, non-infected people, so they are not expressed as a reaction to viral infection. This confirms findings that amyloids are not intrinsically toxic [3] but also raises the question of whether those amyloids encode different functions in addition to assisting infections of pathogenic microbes. Viruses very often depend on multiple host factors for infectivity, the replication of their genetic material or virion assembly, so it is not unlikely that HIV and Ebola viruses have evolved to employ host amyloids to promote their infectivity. Either way, it is currently not known why some amyloids stimulate viral infections and others inhibit their replication. A systematic study of the effect of different amyloids, both disease-associated and not, on viral infectivity could help resolve this question.

Here, we summarized the known interactions between human amyloids and human-infecting viruses and focused on the potential underlying mechanism driving these interactions. We conclude that so far, three different hypotheses have been suggested and we aim to connect these hypotheses to the well-studied mechanisms of amyloid initiation: spontaneous nucleation, SCN, and sequence-specific SN. The three mechanisms of amyloid-virus interactions described here are non-mutually exclusive: viral infection can induce the up-regulation of amyloidogenic proteins or interfere with their degradation, followed by a seeding event on virion surface proteins. Once the aggregation has initiated, soluble oligomeric seeds can specifically bind to viral proteins that express a homologous APR, and in this way, amyloids can interact with viruses in a sequence-specific manner. Whether or not such mechanisms of interaction are indeed broadly used for amyloid virus interactions remains to be determined, but homologous APRs between amyloids and interacting viral proteins have been described. Moreover, we have shown that such interactions can be used in a synthetic biology approach to design antiviral amyloids [158]. By reverseengineering synthetic amyloids that encode a specific viral APR, these amyloids are able to bind to the corresponding viral protein and induce its aggregation. Interestingly, such observations have been made in a physiological context, as well: the herpesvirus protein M45 induces aggregation of two host proteins, NEMO and RIPK1, to block innate antiviral responses [161]. A specific 5-amino acid motif in the C-terminal part of M45 protein recruits the two host proteins and induces their aggregation. The M45-induced sequestration of NEMO and RIPK1 subsequently facilitates their degradation by autophagy. Whether or not this motif engages in an amyloid-like interaction with the host proteins remains to be determined, but in this case, virus-induced host protein aggregation promotes viral infectivity. Of note, this motif acts as a traditional APR as fusion the motif to mCherry is sufficient to induce mCherry aggregation.

Interestingly, multiple viruses have evolved to express amyloid-forming proteins to increase virulence. Rift Valley fever virus (RVFV) expresses a protein called NSs that rapidly organizes into large filamentous structures in the nuclei and to a lesser extent in the cytosol of infected cells. These filaments show the characteristic features of amyloids [162] and have been linked to RVFV virulence. Mice infected with RVFV lacking NSs survive, while those infected with wt RVFV die within a few days as the result of severe encephalitis. Léger et al. [162] showed that the virus employs NSs amyloid formation to suppress IFN 
response to counteract host cell defenses. Moreover, NSs amyloid fibrils were identified in the neurons of intraperitoneally infected mice and it was shown that the NSs are the causative agent for neuropathy.

Unraveling the potential role of disease-associated amyloids in innate immunity against invading pathogens could shed more light on the pathogenic effect of these amyloids and provide new therapeutic opportunities. General antiviral treatments in AD patients already showed some promising effects, but a more specific approach will be needed to obtain conclusive results. Moreover, if amyloids, indeed, encode specific antiviral properties, together with the fact that most amyloids are not intrinsically toxic [3], synthetic or natural amyloids could be used as a new class of antimicrobial peptides (AMPs) [158]. Indeed, the molecular architecture of amyloid structures entails the ability to engage in very specific interactions with other proteins, affecting their biological function.

Acknowledgements The Switch Laboratory was supported by grants from the European Research Council under the European Union's Horizon 2020 Framework Programme ERC Grant agreement 647458 (MANGO) to JS, the Flanders institute for biotechnology (VIB), the University of Leuven ("Industrieel Onderzoeksfonds"), and the Funds for Scientific Research Flanders (FWO (G045920N). E.M. is supported by the Funds for Scientific Research Flanders (FWO) in the shape of a personal fellowship for strategic basic research (application number: $1 \mathrm{~S} 48317 \mathrm{~N})$.

Open Access This article is licensed under a Creative Commons Attribution 4.0 International License, which permits use, sharing, adaptation, distribution and reproduction in any medium or format, as long as you give appropriate credit to the original author(s) and the source, provide a link to the Creative Commons licence, and indicate if changes were made. The images or other third party material in this article are included in the article's Creative Commons licence, unless indicated otherwise in a credit line to the material. If material is not included in the article's Creative Commons licence and your intended use is not permitted by statutory regulation or exceeds the permitted use, you will need to obtain permission directly from the copyright holder. To view a copy of this licence, visit http://creativecommons.org/licenses/by/4.0/.

\section{References}

1. Hippius H, Neundörfer G (2003) The discovery of Alzheimer's disease. Dialog Clin Neurosci 5(1):101-108

2. Eisenberg D, Jucker M (2012) The amyloid state of proteins in human diseases. Cell 148(6):1188-1203

3. Gallardo R, Ramakers M, De Smet F, Claes F, Khodaparast L, Khodaparast L et al (2016) De novo design of a biologically active amyloid. Science 354(6313):4949

4. Pham CL, Kwan AH, Sunde M (2014) Functional amyloid: widespread in Nature, diverse in purpose. Essays Biochem 56:207-219

5. Vogler TO, Wheeler JR, Nguyen ED, Hughes MP, Britson KA, Lester E et al (2018) TDP-43 and RNA form amyloid-like myogranules in regenerating muscle. Nature 563(7732):508-513
6. Eimer WA, Vijaya Kumar DK, Navalpur Shanmugam NK, Rodriguez AS, Mitchell T, Washicosky KJ et al (2018) Alzheimer's Disease-associated $\beta$-amyloid is rapidly seeded by herpesviridae to protect against brain infection. Neuron 99(1):56-63.e3

7. Itzhaki RF (2014) Herpes simplex virus type 1 and Alzheimer's disease: increasing evidence for a major role of the virus. Front Aging Neurosci 6:202

8. Münch J, Rücker E, Ständker L, Adermann K, Goffinet C, Schindler $M$ et al (2007) Semen-derived amyloid fibrils drastically enhance HIV infection. Cell 131(6):1059-1071

9. Chiti F, Dobson CM (2017) Protein misfolding, amyloid formation, and human disease: a summary of progress over the last decade. Annu Rev Biochem 86:27-68

10. Ezzat K, Pernemalm M, Pålsson S, Roberts TC, Järver P, Dondalska A et al (2019) The viral protein corona directs viral pathogenesis and amyloid aggregation. Nat Commun 10(1):2331

11. Frydman J (2001) Folding of newly translated proteins in vivo: the role of molecular chaperones. Annu Rev Biochem 70:603-647

12. Hartl FU, Hayer-Hartl M (2009) Converging concepts of protein folding in vitro and in vivo. Nat Struct Mol Biol 16(6):574-581

13. Richter K, Haslbeck M, Buchner J (2010) The heat shock response: life on the verge of death. Mol Cell 40(2):253-266

14. Dobson CM (2003) Protein folding and misfolding. Nature 426(6968):884-890

15. Haigis MC, Yankner BA (2010) The aging stress response. Mol Cell 40(2):333-344

16. Dubnikov T, Ben-Gedalya T, Cohen E (2017) Protein quality control in health and disease. Cold Spring Harb Perspect Biol 9(3):a023523

17. Fernandez-Escamilla AM, Rousseau F, Schymkowitz J, Serrano L (2004) Prediction of sequence-dependent and mutational effects on the aggregation of peptides and proteins. Nat Biotechnol 22(10):1302-1306

18. Beerten J, Schymkowitz J, Rousseau F (2012) Aggregation prone regions and gatekeeping residues in protein sequences. Curr Top Med Chem 12(22):2470-2478

19. Lee J, Culyba EK, Powers ET, Kelly JW (2011) Amyloid- $\beta$ forms fibrils by nucleated conformational conversion of oligomers. Nat Chem Biol 7(9):602-609

20. Cremades N, Cohen SI, Deas E, Abramov AY, Chen AY, Orte A et al (2012) Direct observation of the interconversion of normal and toxic forms of $\alpha$-synuclein. Cell 149(5):1048-1059

21. Nelson R, Sawaya MR, Balbirnie M, Madsen A, Riekel C, Grothe $\mathrm{R}$ et al (2005) Structure of the cross-beta spine of amyloid-like fibrils. Nature 435(7043):773-778

22. Esteras-Chopo A, Serrano L, Lopez PM (2005) The amyloid stretch hypothesis: recruiting proteins toward the dark side. Proc Natl Acad Sci USA 102(46):16672-16677

23. Giasson BI, Murray IV, Trojanowski JQ, Lee VM (2001) A hydrophobic stretch of 12 amino acid residues in the middle of alpha-synuclein is essential for filament assembly. J Biol Chem 276(4):2380-2386

24. Krebs MR, Morozova-Roche LA, Daniel K, Robinson CV, Dobson CM (2004) Observation of sequence specificity in the seeding of protein amyloid fibrils. Protein Sci 13(7):1933-1938

25. O'Nuallain B, Williams AD, Westermark P, Wetzel R (2004) Seeding specificity in amyloid growth induced by heterologous fibrils. J Biol Chem 279(17):17490-17499

26. Wright CF, Teichmann SA, Clarke J, Dobson CM (2005) The importance of sequence diversity in the aggregation and evolution of proteins. Nature 438(7069):878-881

27. Sawaya MR, Sambashivan S, Nelson R, Ivanova MI, Sievers SA, Apostol MI et al (2007) Atomic structures of amyloid cross-beta spines reveal varied steric zippers. Nature 447(7143):453-457 
28. Zraika S, Hull RL, Verchere CB, Clark A, Potter KJ, Fraser PE et al (2010) Toxic oligomers and islet beta cell death: guilty by association or convicted by circumstantial evidence? Diabetologia 53(6):1046-1056

29. Roberts HL, Brown DR (2015) Seeking a mechanism for the toxicity of oligomeric $\alpha$-synuclein. Biomolecules 5(2):282-305

30. Roberts RF, Wade-Martins R, Alegre-Abarrategui J (2015) Direct visualization of alpha-synuclein oligomers reveals previously undetected pathology in Parkinson's disease brain. Brain 138(Pt 6): $1642-1657$

31. Gath J, Bousset L, Habenstein B, Melki R, Meier BH, Böckmann A (2014) Yet another polymorph of $\alpha$-synuclein: solidstate sequential assignments. Biomol NMR Assign 8(2):395-404

32. Benilova I, Karran E, De Strooper B (2012) The toxic A $\beta$ oligomer and Alzheimer's disease: an emperor in need of clothes. Nat Neurosci 15(3):349-357

33. Hieronymus L, Griffin S (2015) Role of amylin in Type 1 and Type 2 diabetes. Diabetes Educ 41(1 Suppl):47S-56S

34. Parihar MS, Brewer GJ (2010) Amyloid-beta as a modulator of synaptic plasticity. J Alzheimers Dis 22(3):741-763

35. Benskey MJ, Perez RG, Manfredsson FP (2016) The contribution of alpha synuclein to neuronal survival and function - Implications for Parkinson's disease. J Neurochem 137(3):331-359

36. Greten-Harrison B, Polydoro M, Morimoto-Tomita M, Diao L, Williams AM, Nie EH et al (2010) alphabetagamma-Synuclein triple knockout mice reveal age-dependent neuronal dysfunction. Proc Natl Acad Sci USA 107(45):19573-19578

37. Velazquez R, Ferreira E, Tran A, Turner EC, Belfiore R, Branca $C$ et al (2018) Acute tau knockdown in the hippocampus of adult mice causes learning and memory deficits. Aging Cell 17(4):e12775

38. Mulder H, Gebre-Medhin S, Betsholtz C, Sundler F, Ahren B (2000) Islet amyloid polypeptide (amylin)-deficient mice develop a more severe form of alloxan-induced diabetes. Am J Physiol Endocrinol Metab 278(4):E684-E691

39. Maji SK, Perrin MH, Sawaya MR, Jessberger S, Vadodaria K, Rissman RA et al (2009) Functional amyloids as natural storage of peptide hormones in pituitary secretory granules. Science 325(5938):328-332

40. Jackson MP, Hewitt EW (2017) Why are functional amyloids non-toxic in humans? Biomolecules 7(4):71

41. Si K, Choi YB, White-Grindley E, Majumdar A, Kandel ER (2010) Aplysia CPEB can form prion-like multimers in sensory neurons that contribute to long-term facilitation. Cell 140(3):421-435

42. Khan MR, Li L, Pérez-Sánchez C, Saraf A, Florens L, Slaughter BD et al (2015) Amyloidogenic oligomerization transforms Drosophila Orb2 from a translation repressor to an activator. Cell 163(6):1468-1483

43. Hervas R, Rau MJ, Park Y, Zhang W, Murzin AG, Fitzpatrick JAJ et al (2020) Cryo-EM structure of a neuronal functional amyloid implicated in memory persistence in Drosophila. Science 367(6483):1230-1234

44. Chapman MR, Robinson LS, Pinkner JS, Roth R, Heuser J, Hammar M et al (2002) Role of Escherichia coli curli operons in directing amyloid fiber formation. Science 295(5556):851-855

45. Wickner RB, Edskes HK, Bateman DA, Kelly AC, Gorkovskiy A, Dayani Y et al (2013) Amyloids and yeast prion biology. Biochemistry 52(9):1514-1527

46. Prasad A, Bharathi V, Sivalingam V, Girdhar A, Patel BK (2019) Molecular mechanisms of TDP-43 misfolding and pathology in amyotrophic lateral sclerosis. Front Mol Neurosci 12:25
47. Kagan BL, Jang H, Capone R, Teran Arce F, Ramachandran S, Lal R et al (2012) Antimicrobial properties of amyloid peptides. Mol Pharm 9(4):708-717

48. Soscia SJ, Kirby JE, Washicosky KJ, Tucker SM, Ingelsson M, Hyman B et al (2010) The Alzheimer's disease-associated amyloid beta-protein is an antimicrobial peptide. PLoS ONE 5(3):e9505

49. Kumar DK, Choi SH, Washicosky KJ, Eimer WA, Tucker S, Ghofrani J et al (2016) Amyloid- $\beta$ peptide protects against microbial infection in mouse and worm models of Alzheimer's disease. Sci Transl Med. 8(340):340ra72

50. Marreiros R, Müller-Schiffmann A, Trossbach SV, Prikulis I, Hänsch S, Weidtkamp-Peters S et al (2020) Disruption of cellular proteostasis by H1N1 influenza A virus causes $\alpha$-synuclein aggregation. Proc Natl Acad Sci USA 117(12):6741-6751

51. Beatman EL, Massey A, Shives KD, Burrack KS, Chamanian M, Morrison TE et al (2015) Alpha-synuclein expression restricts RNA viral infections in the brain. J Virol 90(6):2767-2782

52. Harris SA, Harris EA (2015) Herpes simplex virus Type 1 and other pathogens are key causative factors in sporadic Alzheimer's disease. J Alzheimers Dis 48(2):319-353

53. Itzhaki RF, Lin WR, Shang D, Wilcock GK, Faragher B, Jamieson GA (1997) Herpes simplex virus type 1 in brain and risk of Alzheimer's disease. Lancet 349(9047):241-244

54. Mawanda F, Wallace R (2013) Can infections cause Alzheimer's disease? Epidemiol Rev 35(1):161-180

55. Wozniak MA, Mee AP, Itzhaki RF (2009) Herpes simplex virus type 1 DNA is located within Alzheimer's disease amyloid plaques. J Pathol 217(1):131-138

56. Wozniak MA, Itzhaki RF, Shipley SJ, Dobson CB (2007) Herpes simplex virus infection causes cellular beta-amyloid accumulation and secretase upregulation. Neurosci Lett 429(2-3):95-100

57. De Chiara G, Marcocci ME, Civitelli L, Argnani R, Piacentini R, Ripoli C et al (2010) APP processing induced by herpes simplex virus type 1 (HSV-1) yields several APP fragments in human and rat neuronal cells. PLoS ONE 5(11):e13989

58. Santana S, Bullido MJ, Recuero M, Valdivieso F, Aldudo J (2012) Herpes simplex virus type I induces an incomplete autophagic response in human neuroblastoma cells. J Alzheimers Dis 30(4):815-831

59. Bourgade K, Dupuis G, Frost EH, Fülöp T (2016) Anti-viral properties of amyloid- $\beta$ peptides. J Alzheimers Dis 54(3):859-878

60. Bourgade K, Garneau H, Giroux G, Le Page AY, Bocti C, Dupuis $\mathrm{G}$ et al (2015) $\beta$-Amyloid peptides display protective activity against the human Alzheimer's disease-associated herpes simplex virus-1. Biogerontology 16(1):85-98

61. Bourgade K, Le Page A, Bocti C, Witkowski JM, Dupuis G, Frost EH et al (2016) Protective effect of amyloid- $\beta$ peptides against herpes simplex virus-1 infection in a neuronal cell culture model. J Alzheimers Dis 50(4):1227-1241

62. Bortolotti D, Gentili V, Rotola A, Caselli E, Rizzo R (2019) HHV-6A infection induces amyloid-beta expression and activation of microglial cells. Alzheimers Res Ther 11(1):104

63. Wozniak MA, Frost AL, Preston CM, Itzhaki RF (2011) Antivirals reduce the formation of key Alzheimer's disease molecules in cell cultures acutely infected with herpes simplex virus type 1. PLoS ONE 6(10):e25152

64. Itzhaki RF (2018) Corroboration of a major role for herpes simplex virus type 1 in Alzheimer's disease. Front Aging Neurosci 10:324

65. Kristen H, Santana S, Sastre I, Recuero M, Bullido MJ, Aldudo J (2015) Herpes simplex virus type 2 infection induces AD-like neurodegeneration markers in human neuroblastoma cells. Neurobiol Aging 36(10):2737-2747 
66. Tsai MC, Cheng WL, Sheu JJ, Huang CC, Shia BC, Kao LT et al (2017) Increased risk of dementia following herpes zoster ophthalmicus. PLoS ONE 12(11):e0188490

67. Chen VC, Wu SI, Huang KY, Yang YH, Kuo TY, Liang HY et al (2018) Herpes zoster and dementia: a nationwide populationbased cohort study. J Clin Psychiatry 79(1):1611m312

68. Lurain NS, Hanson BA, Martinson J, Leurgans SE, Landay AL, Bennett DA et al (2013) Virological and immunological characteristics of human cytomegalovirus infection associated with Alzheimer disease. J Infect Dis 208(4):564-572

69. Chai Q, Jovasevic V, Malikov V, Sabo Y, Morham S, Walsh D et al (2017) HIV-1 counteracts an innate restriction by amyloid precursor protein resulting in neurodegeneration. Nat Commun $8(1): 1522$

70. White MR, Kandel R, Tripathi S, Condon D, Qi L, Taubenberger J et al (2014) Alzheimer's associated $\beta$-amyloid protein inhibits influenza A virus and modulates viral interactions with phagocytes. PLoS ONE 9(7):e101364

71. White MR, Kandel R, Hsieh IN, De Luna X, Hartshorn KL (2018) Critical role of C-terminal residues of the Alzheimer's associated $\beta$-amyloid protein in mediating antiviral activity and modulating viral and bacterial interactions with neutrophils. PLoS ONE 13(3):e0194001

72. Bubak AN, Como CN, Coughlan CM, Johnson NR, Hassell JE, Mescher T et al (2020) Varicella-zoster virus infection of primary human spinal astrocytes produces intracellular amylin, amyloid- $\beta$, and an amyloidogenic extracellular environment. J Infect Dis 221(7):1088-1097

73. Roan NR, Müller JA, Liu H, Chu S, Arnold F, Stürzel CM et al (2011) Peptides released by physiological cleavage of semen coagulum proteins form amyloids that enhance HIV infection. Cell Host Microbe 10(6):541-550

74. Usmani SM, Zirafi O, Müller JA, Sandi-Monroy NL, Yadav JK, Meier C et al (2014) Direct visualization of HIV-enhancing endogenous amyloid fibrils in human semen. Nat Commun 5:3508

75. Bart SM, Cohen C, Dye JM, Shorter J, Bates P (2018) Enhancement of Ebola virus infection by seminal amyloid fibrils. Proc Natl Acad Sci USA 115(28):7410-7415

76. Tang Q, Roan NR, Yamamura Y (2013) Seminal plasma and semen amyloids enhance cytomegalovirus infection in cell culture. J Virol 87(23):12583-12591

77. Zambrano A, Solis L, Salvadores N, Cortés M, Lerchundi R, Otth C (2008) Neuronal cytoskeletal dynamic modification and neurodegeneration induced by infection with herpes simplex virus type 1. J Alzheimers Dis 14(3):259-269

78. Alvarez G, Aldudo J, Alonso M, Santana S, Valdivieso F (2012) Herpes simplex virus type 1 induces nuclear accumulation of hyperphosphorylated tau in neuronal cells. J Neurosci Res 90(5):1020-1029

79. Itabashi S, Arai H, Matsui T, Higuchi S, Sasaki H (1997) Herpes simplex virus and risk of Alzheimer's disease. Lancet 349(9058): 1102

80. Tzeng NS, Chung CH, Lin FH, Chiang CP, Yeh CB, Huang SY et al (2018) Anti-herpetic medications and reduced risk of dementia in patients with herpes simplex virus infections-a Nationwide, population-based cohort study in Taiwan. Neurotherapeutics 15(2):417-429

81. Nath A (2018) Association of herpes viral infections, antiherpetic therapy, and dementia: real or alternative fact? Neurotherapeutics 15(2):415-416

82. Lohse N, Obel N (2016) Update of survival for persons With HIV infection in denmark. Ann Intern Med 165(10):749-750
83. Antinori A, Arendt G, Becker JT, Brew BJ, Byrd DA, Cherner $M$ et al (2007) Updated research nosology for HIV-associated neurocognitive disorders. Neurology 69(18):1789-1799

84. McCall S, Henry JM, Reid AH, Taubenberger JK (2001) Influenza RNA not detected in archival brain tissues from acute encephalitis lethargica cases or in postencephalitic Parkinson cases. J Neuropathol Exp Neurol 60(7):696-704

85. Easterbrook JD, Kash JC, Sheng ZM, Qi L, Gao J, Kilbourne ED et al (2011) Immunization with 1976 swine H1N1- or 2009 pandemic H1N1-inactivated vaccines protects mice from a lethal 1918 influenza infection. Influenza Other Respir Viruses 5(3):198-205

86. Vlajinac H, Dzoljic E, Maksimovic J, Marinkovic J, Sipetic S, Kostic V (2013) Infections as a risk factor for Parkinson's disease: a case-control study. Int J Neurosci 123(5):329-332

87. Robinson RL, Shahida S, Madan N, Rao S, Khardori N (2003) Transient parkinsonism in West Nile virus encephalitis. Am J Med 115(3):252-253

88. Jang H, Boltz DA, Webster RG, Smeyne RJ (2009) Viral Parkinsonism. Biochim Biophys Acta 1792(7):714-721

89. Hartman K, Brender JR, Monde K, Ono A, Evans ML, Popovych $\mathrm{N}$ et al (2013) Bacterial curli protein promotes the conversion of PAP248-286 into the amyloid SEVI: cross-seeding of dissimilar amyloid sequences. PeerJ 1:e5

90. Allison ME, Wreghitt T, Palmer CR, Alexander GJ (1994) Evidence for a link between hepatitis $\mathrm{C}$ virus infection and diabetes mellitus in a cirrhotic population. J Hepatol 21(6):1135-1139

91. Grimbert S, Valensi P, Lévy-Marchal C, Perret G, Richardet JP, Raffoux C et al (1996) High prevalence of diabetes mellitus in patients with chronic hepatitis C. A case-control study. Gastroenterol Clin Biol 20(6-7):544-548

92. Mehta HB, Mehta V, Goodwin JS (2017) Association of hypoglycemia with subsequent dementia in older patients with type 2 diabetes mellitus. J Gerontol A Biol Sci Med Sci 72(8):1110-1116

93. White DL, Ratziu V, El-Serag HB (2008) Hepatitis C infection and risk of diabetes: a systematic review and meta-analysis. $\mathrm{J}$ Hepatol 49(5):831-844

94. Mason AL, Lau JY, Hoang N, Qian K, Alexander GJ, Xu L et al (1999) Association of diabetes mellitus and chronic hepatitis C virus infection. Hepatology 29(2):328-333

95. Chen HF, Li CY, Chen P, See TT, Lee HY (2006) Seroprevalence of hepatitis $\mathrm{B}$ and $\mathrm{C}$ in type 2 diabetic patients. J Chin Med Assoc 69(4):146-152

96. Jadoon NA, Shahzad MA, Yaqoob R, Hussain M, Ali N (2010) Seroprevalence of hepatitis $\mathrm{C}$ in type 2 diabetes: evidence for a positive association. Virol $\mathrm{J}$ 7:304

97. Harris MA, Tsui JK, Marion SA, Shen H, Teschke K (2012) Association of Parkinson's disease with infections and occupational exposure to possible vectors. Mov Disord 27(9):1111-1117

98. Massey AR, Beckham JD (2016) Alpha-synuclein, a novel viral restriction factor hiding in plain sight. DNA Cell Biol 35(11):643-645

99. Wu T, Hallett M, Chan P (2015) Motor automaticity in Parkinson's disease. Neurobiol Dis 82:226-234

100. Ogata A, Tashiro K, Nukuzuma S, Nagashima K, Hall WW (1997) A rat model of Parkinson's disease induced by Japanese encephalitis virus. J Neurovirol 3(2):141-147

101. Bantle CM, Phillips AT, Smeyne RJ, Rocha SM, Olson KE, Tjalkens RB (2019) Infection with mosquito-borne alphavirus induces selective loss of dopaminergic neurons, neuroinflammation and widespread protein aggregation. NPJ Parkinsons Dis 5:20

102. Niklasson B, Lindquist L, Klitz W, Englund E (2020) Picornavirus identified in Alzheimer's disease brains: a pathogenic path? J Alzheimers Dis Rep 4(1):141-146 
103. Michaels TC, Liu LX, Meisl G, Knowles TP (2017) Physical principles of filamentous protein self-assembly kinetics. J Phys Condens Matter 29(15):153002

104. Malmberg M, Malm T, Gustafsson O, Sturchio A, Graff C, Espay AJ et al (2020) Disentangling the amyloid pathways: a mechanistic approach to etiology. Front Neurosci 14:256

105. Chiti F, Taddei N, Baroni F, Capanni C, Stefani M, Ramponi G et al (2002) Kinetic partitioning of protein folding and aggregation. Nat Struct Biol 9(2):137-143

106. Kim W, Hecht MH (2008) Mutations enhance the aggregation propensity of the Alzheimer's A beta peptide. J Mol Biol 377(2):565-574

107. Auer S, Dobson CM, Vendruscolo M (2007) Characterization of the nucleation barriers for protein aggregation and amyloid formation. Hfsp j 1(2):137-146

108. Konno T, Ross OA, Puschmann A, Dickson DW, Wszolek ZK (2016) Autosomal dominant Parkinson's disease caused by SNCA duplications. Parkinsonism Relat Disord. 22(Suppl 1):1-6

109. Lott IT, Head E (2019) Dementia in Down syndrome: unique insights for Alzheimer disease research. Nat Rev Neurol 15(3):135-147

110. Shin Y, Brangwynne CP (2017) Liquid phase condensation in cell physiology and disease. Science 357(6357):eaaf4382

111. Koga H, Kaushik S, Cuervo AM (2011) Protein homeostasis and aging: the importance of exquisite quality control. Ageing Res Rev 10(2):205-215

112. Nixon RA, Cataldo AM, Mathews PM (2000) The endosomallysosomal system of neurons in Alzheimer's disease pathogenesis: a review. Neurochem Res 25(9-10):1161-1172

113. Santarelli R, Granato M, Pentassuglia G, Lacconi V, Gilardini Montani MS, Gonnella R et al (2016) KSHV reduces autophagy in THP-1 cells and in differentiating monocytes by decreasing CAST/calpastatin and ATG5 expression. Autophagy 12(12):2311-2325

114. Gilardini Montani MS, Santarelli R, Granato M, Gonnella R, Torrisi MR, Faggioni A et al (2019) EBV reduces autophagy, intracellular ROS and mitochondria to impair monocyte survival and differentiation. Autophagy 15(4):652-667

115. Cirone M (2018) EBV and KSHV infection dysregulates autophagy to optimize viral replication, prevent immune recognition and promote tumorigenesis. Viruses 10(11):599

116. Romeo MA, Faggioni A, Cirone M (2019) Could autophagy dysregulation link neurotropic viruses to Alzheimer's disease? Neural Regen Res 14(9):1503-1506

117. Romeo MA, Masuelli L, Gaeta A, Nazzari C, Granato M, Gilardini Montani MS et al (2019) Impact of HHV-6A and HHV-6B lytic infection on autophagy and endoplasmic reticulum stress. J Gen Virol 100(1):89-98

118. Granato M, Santarelli R, Farina A, Gonnella R, Lotti LV, Faggioni A et al (2014) Epstein-barr virus blocks the autophagic flux and appropriates the autophagic machinery to enhance viral replication. J Virol 88(21):12715-12726

119. Granato M, Santarelli R, Filardi M, Gonnella R, Farina A, Torrisi MR et al (2015) The activation of KSHV lytic cycle blocks autophagy in PEL cells. Autophagy 11(11):1978-1986

120. Orvedahl A, Levine B (2008) Viral evasion of autophagy. Autophagy 4(3):280-285

121. Buckingham EM, Carpenter JE, Jackson W, Zerboni L, Arvin AM, Grose C (2015) Autophagic flux without a block differentiates varicella-zoster virus infection from herpes simplex virus infection. Proc Natl Acad Sci USA 112(1):256-261

122. Hogestyn JM, Mock DJ, Mayer-Proschel M (2018) Contributions of neurotropic human herpesviruses herpes simplex virus 1 and human herpesvirus 6 to neurodegenerative disease pathology. Neural Regen Res 13(2):211-221
123. Komatsu M, Waguri S, Chiba T, Murata S, Iwata J, Tanida I et al (2006) Loss of autophagy in the central nervous system causes neurodegeneration in mice. Nature 441(7095):880-884

124. Uddin MS, Stachowiak A, Mamun AA, Tzvetkov NT, Takeda S, Atanasov AG et al (2018) Autophagy and Alzheimer's disease: from molecular mechanisms to therapeutic implications. Front Aging Neurosci 10:04

125. Metaxakis A, Ploumi C, Tavernarakis N (2018) Autophagy in age-associated neurodegeneration. Cells 7(5):37

126. Zhou F, van Laar T, Huang H, Zhang L (2011) APP and APLP1 are degraded through autophagy in response to proteasome inhibition in neuronal cells. Protein Cell 2(5):377-383

127. Wang Y, Mandelkow E (2012) Degradation of tau protein by autophagy and proteasomal pathways. Biochem Soc Trans 40(4):644-652

128. Nilsson P, Loganathan K, Sekiguchi M, Matsuba Y, Hui K, Tsubuki $S$ et al (2013) A $\beta$ secretion and plaque formation depend on autophagy. Cell Rep 5(1):61-69

129. Hui L, Chen X, Haughey NJ, Geiger JD (2012) Role of endolysosomes in HIV-1 Tat-induced neurotoxicity. ASN Neuro 4(4):243-252

130. Achim CL, Adame A, Dumaop W, Everall IP, Masliah E (2009) Increased accumulation of intraneuronal amyloid beta in HIVinfected patients. J Neuroimmune Pharmacol 4(2):190-199

131. Civitelli L, Marcocci ME, Celestino I, Piacentini R, Garaci E, Grassi C et al (2015) Herpes simplex virus type 1 infection in neurons leads to production and nuclear localization of APP intracellular domain (AICD): implications for Alzheimer's disease pathogenesis. J Neurovirol 21(5):480-490

132. Kanemitsu H, Tomiyama T, Mori H (2003) Human neprilysin is capable of degrading amyloid beta peptide not only in the monomeric form but also the pathological oligomeric form. Neurosci Lett 350(2):113-116

133. Iwata N, Tsubuki S, Takaki Y, Shirotani K, Lu B, Gerard NP et al (2001) Metabolic regulation of brain Abeta by neprilysin. Science 292(5521):1550-1552

134. Hooper C, Killick R, Lovestone S (2008) The GSK3 hypothesis of Alzheimer's disease. J Neurochem 104(6):1433-1439

135. Sil S, Hu G, Liao K, Niu F, Callen S, Periyasamy P et al (2020) HIV-1 Tat-mediated astrocytic amyloidosis involves the HIF-1 $\alpha /$ IncRNA BACE1-AS axis. PLoS Biol 18(5):e3000660

136. Faghihi MA, Zhang M, Huang J, Modarresi F, Van der Brug MP, Nalls MA et al (2010) Evidence for natural antisense transcript-mediated inhibition of microRNA function. Genome Biol 11(5):R56

137. Zheng K, Liu Q, Wang S, Ren Z, Kitazato K, Yang D et al (2018) HSV-1-encoded microRNA miR-H1 targets Ubr1 to promote accumulation of neurodegeneration-associated protein. Virus Genes 54(3):343-350

138. John T, Gladytz A, Kubeil C, Martin LL, Risselada HJ, Abel B (2018) Impact of nanoparticles on amyloid peptide and protein aggregation: a review with a focus on gold nanoparticles. Nanoscale 10(45):20894-20913

139. Habchi J, Chia S, Galvagnion C, Michaels TCT, Bellaiche MMJ, Ruggeri FS et al (2018) Cholesterol catalyses A $\beta 42$ aggregation through a heterogeneous nucleation pathway in the presence of lipid membranes. Nat Chem 10(6):673-683

140. Potter H, Wisniewski T (2012) Apolipoprotein e: essential catalyst of the Alzheimer amyloid cascade. Int J Alzheimers Dis 2012:489428

141. Linse S, Cabaleiro-Lago C, Xue WF, Lynch I, Lindman S, Thulin E et al (2007) Nucleation of protein fibrillation by nanoparticles. Proc Natl Acad Sci U S A 104(21):8691-8696

142. Iannuzzi C, Irace G, Sirangelo I (2015) The effect of glycosaminoglycans (GAGs) on amyloid aggregation and toxicity. Molecules 20(2):2510-2528 
143. Penke B, Paragi G, Gera J, Berkecz R, Kovács Z, Crul T et al (2018) The role of lipids and membranes in the pathogenesis of Alzheimer's disease: a comprehensive view. Curr Alzheimer Res 15(13):1191-1212

144. Liu C, Zhang Y (2011) Nucleic acid-mediated protein aggregation and assembly. Adv Protein Chem Struct Biol 84:1-40

145. Liang S, Wang Z, Yuan J, Zhang J, Dai X, Qin F et al (2019) Rapid identification of tanshinone IIA metabolites in an amyloid- $\beta(1-42)$ induced Alzherimer's disease rat model using uhplc-q-exactive qrbitrap mass spectrometry. Molecules 24(14):2584

146. Törnquist M, Michaels TCT, Sanagavarapu K, Yang X, Meisl G, Cohen SIA et al (2018) Secondary nucleation in amyloid formation. Chem Commun (Camb) 54(63):8667-8684

147. Roan NR, Münch J, Arhel N, Mothes W, Neidleman J, Kobayashi A et al (2009) The cationic properties of SEVI underlie its ability to enhance human immunodeficiency virus infection. J Virol 83(1):73-80

148. Ahyayauch H, Raab M, Busto JV, Andraka N, Arrondo JL, Masserini $\mathrm{M}$ et al (2012) Binding of $\beta$-amyloid (1-42) peptide to negatively charged phospholipid membranes in the liquidordered state: modeling and experimental studies. Biophys $\mathbf{J}$ 103(3):453-463

149. Chen J, Ren R, Tan S, Zhang W, Zhang X, Yu F et al (2015) A peptide derived from the HIV-1 gp120 coreceptor-binding region promotes formation of PAP248-286 amyloid fibrils to enhance HIV-1 infection. PLoS ONE 10(12):e0144522

150. Chen J, Ren R, Yu F, Wang C, Zhang X, Li W et al (2017) A degraded fragment of HIV-1 Gp120 in rat hepatocytes forms fibrils and enhances HIV-1 infection. Biophys $J$ 113(7):1425-1439

151. Hategan A, Bianchet MA, Steiner J, Karnaukhova E, Masliah E, Fields A et al (2017) HIV Tat protein and amyloid- $\beta$ peptide form multifibrillar structures that cause neurotoxicity. Nat Struct Mol Biol 24(4):379-386

152. Cribbs DH, Azizeh BY, Cotman CW, LaFerla FM (2000) Fibril formation and neurotoxicity by a herpes simplex virus glycoprotein B fragment with homology to the Alzheimer's A beta peptide. Biochemistry 39(20):5988-5994

153. Yankner BA, Dawes LR, Fisher S, Villa-Komaroff L, OsterGranite ML, Neve RL (1989) Neurotoxicity of a fragment of the amyloid precursor associated with Alzheimer's disease. Science 245(4916):417-420

154. Halverson K, Fraser PE, Kirschner DA, Lansbury PT Jr (1990) Molecular determinants of amyloid deposition in Alzheimer's disease: conformational studies of synthetic beta-protein fragments. Biochemistry 29(11):2639-2644

155. Singh VK, Kumar S, Tapryal S (2020) Aggregation propensities of herpes simplex virus-1 proteins and derived peptides: an in silico and in vitro analysis. ACS Omega 5(22):12964-12973

156. Thorburn K, Hart CA (2006) Think outside the box: extrapulmonary manifestations of severe respiratory syncytial virus infection. Crit Care 10(4):159

157. Kokotidou C, Jonnalagadda SVR, Orr AA, Seoane-Blanco M, Apostolidou CP, van Raaij MJ et al (2018) A novel amyloid designable scaffold and potential inhibitor inspired by GAIIG of amyloid beta and the HIV-1 V3 loop. FEBS Lett 592(11): 1777-1788

158. Michiels E, Roose K, Gallardo R, Khodaparast L, Khodaparast L, van der Kant R et al (2020) Reverse engineering synthetic antiviral amyloids. Nat Commun 11(1):2832

159. Zhang SM, Liao Y, Neo TL, Lu Y, Liu DX, Vahlne A et al (2018) Identification and application of self-binding zipper-like sequences in SARS-CoV spike protein. Int J Biochem Cell Biol 101:103-112

160. Dobson CM (2017) The amyloid phenomenon and its links with human disease. Cold Spring Harb Perspect Biol. 9(6):a023648

161. Muscolino E, Schmitz R, Loroch S, Caragliano E, Schneider C, Rizzato $\mathrm{M}$ et al (2020) Herpesviruses induce aggregation and selective autophagy of host signalling proteins NEMO and RIPK1 as an immune-evasion mechanism. Nat Microbiol 5(2):331-342

162. Leger P, Nachman E, Richter K, Tamietti C, Koch J, Burk R et al (2020) NSs amyloid formation is associated with the virulence of Rift Valley fever virus in mice. Nat Commun 11(1):3281

Publisher's Note Springer Nature remains neutral with regard to jurisdictional claims in published maps and institutional affiliations. 